\title{
Uma Aplicação de Dados em Painel para as Despesas Públicas dos Municípios do Espírito Santo
}

\section{Edson Zambon Monte*}

\begin{abstract}
Resumo: Este trabalho objetivou estimar a demanda por bens públicos nos municípios do Espírito Santo, em nível de despesa total e de despesas funcionais. O trabalho baseou-se no modelo do eleitor mediano, utilizando da técnica de dados em painel. De acordo com os resultados, os bens públicos são de primeira necessidade para as comunidades dos municípios capixabas. As transferências intergovernamentais mostraram-se fortemente significativas na determinação da despesa total e nas despesas por funções. O parâmetro de congestionamento revelou que existem economias de escala a serem exploradas para os bens públicos locais no Espírito Santo.
\end{abstract}

Classificação JEL: C31, H70, H72.

Palavras-chave: teoria do eleitor mediano; dados em painel; Espírito Santo.

An Application of Panel Data for Public Expenditure in the Municipalities of Espírito Santo

Abstract: The objective of this paper was to estimate the demand for local public ser-
vices of Espírito Santo, in level of total expenditure and of functional expenses. The
study was based on the median voter theory and adopted the panel data technique. Ac-
cording to results, the local public goods are essential (or normal). Intergovernmental
transfers were significant in determining the total expenditure and the expenditure by
functions. The congestion coefficient showed a value less than unity. Thus, there is the
presence of economies of scale to be exploited for public goods in the Espírito Santo.

Keywords: median voter theory; panel data; Espírito Santo.

JEL Classification: C31, H70, H72.

\footnotetext{
Professor do Departamento de Economia da Universidade Federal do Espírito Santo (UFES). E-
} -mail: edsonzambon@yahoo.com.br 


\section{Introdução}

Segundo Giambiagi e Além (2000) existem funções que são eminentemente do governo, sendo que algumas delas também são realizadas pelo setor privado. Entre as mais importantes estão: a) saúde; b) educação; c) defesa nacional; d) policiamento; e) regulação; f) justiça; e, g) assistencialismo. Essas funções impactam diretamente nas despesas do setor público. Ainda, segundo os autores, os gastos públicos elevaram-se fortemente ao longo do século XX, devido, principalmente, aos seguintes fatores: i) fatores demográficos associados ao envelhecimento progressivo da população; ii) urbanização; iii) crescimento do Produto Interno Bruto - PIB per-capita; e, iv) aumento do preço relativo dos serviços.

Entre as correntes que estudam a questão dos gastos públicos ${ }^{1}$, uma delas é a teoria da escolha pública ${ }^{2}$ (public choice), que começou a ser desenvolvida em meados da década de 1950, ganhando ênfase com estudos realizados por Samuelson (1954). Posteriormente, avanços teóricos puderam ser vistos por Tibeout (1956), que considerou que os serviços fornecidos por governos locais são diferentes quando cidadãos tem livre mobilidade. Isto é, se um indivíduo, que transita de uma comunidade para outra, depara-se com diferentes níveis e tipos de serviços públicos prestados, esse escolherá o local que melhor satisfaça suas necessidades particulares. Tal fator resultaria em comunidades homogêneas e com serviços públicos similares (devido à competição entre as jurisdições) e, em uma situação de equilíbrio e com mercado eficiente, não seria possível um cidadão melhorar sua situação e recorrer a diferentes alternativas.

Até o início da década de 1970 era difícil justificar as escolhas das variáveis que determinavam os gastos públicos, pois as pesquisas empíricas eram baseadas em abordagens ad hoc. (BERGSTROM; GOODMAN, 1973). Conforme Barcelos (2007), no período, embora os modelos propostos contassem com inúmeras variáveis para analisar os gastos públicos, havia muita dificuldade em explicar a escolha dessas variáveis. A partir de 1970, uma série de estudos objetivou verificar os determinantes das despesas públicas fundamentando-se nos pressupostos microeconômicos da teoria do consumidor, tendo, como semelhança, a utilização da teoria do eleitor mediano, desenvolvida inicialmente por Bowen (1943), Black (1948),

\footnotetext{
Nesta pesquisa, gastos e despesas públicas serão sinônimos.

2 Em Stiglitz (2000) é possível encontrar uma visão geral sobre a teoria da escolha pública. É importante dizer que, de acordo com Pereira (1997), a teoria da escolha pública foi a principal crítica teórica econômica que respalda a intervenção do estado na economia - a economia do bem-estar. Nesse ponto, não há concordância entre o tamanho e a importância do estado na economia. Enquanto a teoria do bem-estar justifica a intervenção do governo pelos fracassos econômicos, a teoria da escolha pública veio clarificar os fracassos do governo e postular limites para a intervenção do governo na economia. Ainda, de acordo com Pereira (1997), a teoria da escolha pública trata-se de um programa de investigação, enquanto o pensamento neoliberal de uma ideologia. As duas coisas, portanto, não devem ser confundidas.
} 
Downs (1957), entre outros. Na teoria do eleitor mediano a demanda comunitária é determinada pelo conjunto das demandas individuais de cada cidadão. Dessa forma, essa teoria considera que "os candidatos formulam políticas com o intuito de ganhar eleições, ao invés de ganhar as eleições para formular políticas” (DOWNS, 1957, p. 28).

Mesmo tendo recebido algumas críticas ${ }^{3}$, estudos vêm demonstrando a robustez do modelo do eleitor mediano, sendo esse considerado válido no que se refere ao comportamento do eleitor mediano determinar o comportamento fiscal do governo. Em nível internacional, pode-se citar os estudos de Borcherding e Deacon (1972), Bergstrom e Goodman (1973), Pommerehne (1978), Edwards (1990), Turnbull e Djoundourian (1994), Aronsson et al. (2000) e Sanz e Velazquez (2002). No Brasil, entre os estudos sobre despesas públicas a nível municipal, tem-se: Mendes (2005), Mendes e Souza (2006) e Barcelos (2007). Utilizando a teoria do eleitor mediano, Mendes (2005) estimou uma curva de demanda dos serviços públicos dos municípios brasileiros, considerando, como variável dependente, entre outras, a despesa global. Estudo semelhante foi realizado por Mendes e Souza (2006), considerando como variável dependente a despesa global per-capita. Barcelos (2007) analisou a demanda por bens públicos locais a partir da despesa orçamentária total e setorial dos municípios brasileiros.

Conforme Rezende (2001), a demanda por um bem público envolve duas reações de sentidos opostos. A primeira refere-se à satisfação advinda do próprio consumo, que depende da utilidade atribuída pelo indivíduo ao bem considerado. A segunda diz respeito ao pagamento de tributos (visto como sacrifício ou desutilidade) para financiar a produção de bens públicos. Esse sacrifício reduz a renda disponível para o consumo de bens privados.

Levando-se em consideração que os gastos públicos vêm aumentando nas últimas décadas, e que os indivíduos são parte "financiadora" desses gastos, ganha cada vez mais ênfase os olhares para o controle dessas despesas, seja em função de como financiá-las, de como realizá-las ou em como priorizar a destinação (aplicação) das mesmas. Assim, este trabalho teve como objetivo estimar a demanda por bens públicos locais (municipais) no estado do Espírito Santo, em nível de despesa total e em nível de despesas funcionais tais $\operatorname{como}^{4}$ : a) gabinete; b) agricultura; d) educação e cultura; e) desenvolvimento urbano; e, f) seguridade social.

Vale ressaltar que, a análise desse artigo compreendeu o período de 2005 a $2012^{5}$, abrangendo dois períodos legislativos completos, no que se refere à adminis-

3 Mesmo sendo bastante difundida, a teoria do eleitor mediano tem recebido algumas críticas. Uma delas refere-se à agregação de preferências individuais para representar uma comunidade como um todo. Conforme Mendes (2005), outros problemas são: erros de medida e presença de heteroscedasticidade entre as variáveis, o que pode comprometer os resultados.

4 A classificação das despesas funcionais está baseada em Barcelos (2007).

5 Destaca-se que, para algumas variáveis estudadas, como o Índice FIRJAM de Desenvolvimento Municipal (IFDM), não existem dados anteriores à 2005, além de que, alguns municípios não apre- 
tração municipal, para os 78 municípios do Espírito Santo. De acordo com relatório da Secretaria de Estado da Fazenda do Espírito Santo (SEFAZ/ES, 2016), as contas públicas do Espírito Santo, no início de 2003, "refletiam um quadro de baixa capacidade de arrecadação, descontrole de gastos e alto nível de endividamento junto a servidores e fornecedores, configurando um perfil claramente insustentável”. Isso refletia diretamente na arrecadação e, consequentemente, nos gastos realizados pelos municípios capixabas. Com a reestruturação do estado, o desempenho da arrecadação dos tributos estaduais impactou fortemente as finanças dos municípios capixabas, que assistiram a um aumento das transferências constitucionais e voluntárias por parte do governo estadual.

Nesse contexto, com o também crescente aumento das transferências federais, as receitas municipais tiveram significativo aumento. Se por um lado isso pode ser visto como um ponto positivo para os municípios, por outro, passou a vigor certa dependência dos mesmos, em relação às transferências intergovernamentais, realidade essa vivida por grande parte dos municípios brasileiros. No caso do Espírito Santo, com algumas exceções, os municípios com menor dependência das transferências intergovernamentais são aqueles localizados na região metropolitana do estado (Cariacica, Guarapari, Viana, Vila Velha e Vitória), que possuem maiores fontes de recursos próprios. Conforme Cossio e Carvalho (2001, p. 76), "apesar do seu caráter necessário e benéfico, o sistema de transferências intergovernamentais não está isento de custos. Em particular, as transferências abrem espaço para a subvaloração dos custos dos bens públicos locais e para uma ampliação excessiva de sua demanda".

Por fim, destaca-se que, mesmo sendo um importante tema para pesquisas, seja a nível nacional ou internacional, abordagens mais empíricas (por exemplo, econométricas) ainda são pouco utilizadas no contexto das despesas públicas em nível do estado e dos municípios do Espírito Santo, sendo esse o foco desta pesquisa.

O presente artigo está estruturado da seguinte forma. Além dessa introdução, a seção 2 traz a descrição do modelo do eleitor mediano. Na seção 3 apresentam-se os modelos de dados em painel de efeitos fixos e aleatórios. As análises estatísticas são demonstradas na seção 4. Por fim, as conclusões são apresentadas na seção 5.

\section{Modelo econômico}

Segundo Mendes (2005) e Mendes e Souza (2006), a formulação matemática da teoria do eleitor mediano pode ser apresentada como segue. No modelo do eleitor mediano os indivíduos maximizam uma função de utilidade, escolhendo

sentam informação para certas variáveis. No mais, o estudo também fez o uso da variável Produto Interno Bruto (PIB), sendo está somente disponibilizada até o ano de 2013, pelo Instituto Brasileiro de Geografia e Estatística (IBGE). Logo, para utilizar períodos legislativos municipais completos, foi adotado o período de 2005 a 2012. 
entre dois bens, $x$ (privado) e $z$ (público), e sujeitos a uma restrição orçamentária. Assume-se que o preço do bem privado é igual a 1 (um), e que todos as pessoas dentro de uma mesma localidade consomem a mesma quantidade do bem público (preço $p_{z}$ ).

Assim, o leitor mediano exerce seu poder de voto buscando maximizar a função de utilidade expressa na equação 1:

$$
U=U\left(x_{i}, z\right),
$$

sendo que essa maximização está sujeita a uma restrição orçamentária (equação 2):

$$
y_{m}=x+t_{i} b_{m},
$$

em que $y_{m}$ é a renda do eleitor mediano; $b_{m}$, base do imposto; e, $t_{i}$, parcela do imposto.

No caso das demandas individuais, essas também dependem da restrição orçamentária do governo, conforme equação 3:

$$
\not=G+B
$$

em que $c$ é o custo médio ou marginal constante da produção do serviço público; $\boldsymbol{B}$, receitas totais dos impostos; e, $G$, transferências intergovernamentais recebidas pela comunidade. Resolvendo a equação 3 para $t$, chega-se a equação 4:

$$
t=\frac{[Z-G]}{B} \text {. }
$$

Bocherding e Deacon (1972) demonstraram que, devido ao congestionamento (rivalidade), o consumo do bem público depende não somente do seu volume total $(Z)$, mas também do tamanho da população de determinada comunidade $(N)$ . Dessa maneira, baseando-se nos autores, descreve-se a função congestionamento, conforme equação 5 :

$$
Z=N^{\gamma} z
$$

em que $\gamma$ representa o efeito congestionamento ou rivalidade. Esse parâmetro também pode ser considerado uma medida de publicização do bem, já que reflete sua maior característica; a não-rivalidade.

Caso $\gamma$ seja igual a unidade, o bem é tipicamente privado, não havendo benefícios de economias de escala para sociedade e, sendo o consumo individual, igual a $1 / N$. Quando $\gamma$ for igual a zero, o bem é público puro (o bem é indivisível e não rival). Se $\gamma$ for maior que um o bem é considerado supercongestionado marginalmente. Por fim, em situações em que $\gamma$ está entre zero e um, o bem é considerado 
semipúblico (ou semiprivado), com certos padrões de congestionamento, mas com economias de escala a serem exploradas.

Tomando-se as equações 4 e 5, e substituindo-as na equação 2 (restrição orçamentária do eleitor mediano), encontra-se a equação 6:

$$
y_{a}=y_{m}+g\left(\frac{b_{m}}{b}\right)=x+\left(\frac{b_{m}}{b}\right) N^{\gamma-1} z,
$$

em que $y_{a}$ é a receita média aumentada por uma parcela das transferências intergovernamentais per capita; $g=G / N$; e, $b=B / N$, sendo $B$ a base do imposto total local. A renda total do eleitor mediano deve cobrir suas despesas privadas e sua parcela de custo na aquisição do serviço público $\left(b_{m} / b\right) \mathbb{N}^{\gamma-1} z$. A equação 6 pode ser reescrita, dando origem a equação 7 :

$$
x=y_{m}+\left(\frac{b_{m}}{b}\right)\left[g-\mathbb{N}^{\gamma-1} z\right] .
$$

Ao inserir a equação 7 na equação 1, chega-se a equação 8:

$$
\max U=U\left[y_{m}+\left(\frac{b_{m}}{b}\right)\left[g-N^{\gamma-1} z\right], z\right] .
$$

Agora, supondo-se que a maximização da equação 8 leva a função de demanda do eleitor mediano, para um serviço público local $(z)$, obtém-se a equação 9:

$$
z=z\left[y_{a}, \frac{b_{m}}{b}, N\right] \text {. }
$$

Considerando-se o preço do serviço público (tax-price) como o custo individual de se adquirir uma unidade adicional de serviço público local, ele pode ser derivado diferenciando-se $y_{a}$ com relação à $z$. Tem-se, então, o preço do imposto dado pela equação 10:

$$
\frac{\delta y_{a}}{\delta z}=p=\left(\frac{b_{m}}{b}\right) N^{\gamma-1}
$$


O consumidor sabe seu próprio custo ou preço do imposto e é capaz de determinar a quantidade de serviço ${ }^{6}$ para a comunidade. Ao supor que a função de demanda da equação $9\left[z=f\left(p_{i}, y_{a}\right]\right.$ possui elasticidades de renda e de preço constantes, determina-se a equação 11:

$$
z=\alpha p^{\beta_{1}} y_{a}^{\beta_{2}} .
$$

Substituindo a equação 10 na equação 11 , a demanda de $z$ fica expressa por:

$$
z=\alpha\left[\left(\frac{b_{m}}{b}\right) d^{\gamma-1}\right]^{\beta_{1}} y_{a}^{\beta_{2}} .
$$

Inserindo-se a equação 12 na equação 5 , encontra-se a equação 13 :

$$
Z=\mathbb{N}^{\gamma}=\alpha\left[\left(\frac{b_{m}}{b}\right) N^{\gamma-1}\right]^{\beta_{1}} y_{a}^{\beta_{2}} N^{\gamma} .
$$

Por fim, incluindo um vetor $\Omega$ de características socioeconômicas ${ }^{7}$, que se acredita, afetam a demanda por bens públicos, e multiplicando a equação 13 por $p$ , tem-se uma função estimável da despesa pública municipal $(E)$, dada pela equação 14:

$$
E=\not 2=p z N^{\gamma}=\alpha\left[\left(\frac{b_{m}}{b}\right) N^{\gamma-1}\right]^{\beta_{1}} y_{a}^{\beta_{2}} N^{\gamma} \Omega^{\beta_{i}} .
$$

Aplicando a propriedade logarítmica ${ }^{8}$, a equação para analisar as despesas públicas municipais fica expressa por:

6 "Existem três razões que podem explicar o porquê dos eleitores perceberem, as vezes, de maneira errada os custos dos serviços públicos: ilusão fiscal, efeito flypaper e, complexidade da receita" (REITER e WEICHENRIEDER, 1997, p. 21).

7 Cabe mencionar aqui que, alguns trabalhos, em nível internacional e nacional, adotaram variáveis socioeconômicas tais como: índice municipal de desenvolvimento humano, esperança de vida, taxa de alfabetização, intensidade da pobreza, percentual da população rural, percentual da população urbana, entre outras. No entanto, como a maioria dessas variáveis é censitária, dado o período de estudo deste trabalho, as mesmas não puderam ser utilizadas, conforme poderá ser verificado na seção resultados.

8 A transformação logarítmica foi realizada para linearizar os coeficientes do modelo e para que os coeficientes fossem interpretados como elasticidades. 
h $E=k+\beta_{1}\left[\mathrm{~h}\left(\frac{b_{m}}{b}\right)\right]+\beta_{2} \mathrm{~h}\left(y_{a}\right)+\beta_{3} \mathrm{~h}(N)+\sum_{i=4}^{n} \beta_{i}\left(\mathrm{~h} \Omega_{i}\right)+\varepsilon_{i}$,

em que $k=\mathrm{h} \alpha+\beta_{1} \mathrm{~h} c ; \beta_{1}$, elasticidade-preço da demanda; e, $\beta_{3}$ (elasticidade-população), satisfaz a equação 16 :

$$
\beta_{3}=\gamma\left(1+\beta_{1}\right)-\beta_{1} \text {. }
$$

\section{Modelo analítico}

\subsection{Dados em painel}

A análise de regressão é um dos pontos mais importantes da análise econométrica, onde se busca verificar, descrever e estimar relações entre dois tipos de variáveis, a saber: variável dependente (ou variável a ser explicada) e variável(eis) independente(s) ou explicativa(s).

Nesta pesquisa foi utilizado como referencial econométrico a abordagem em dados em painel (ou dados longitudinais). Esse instrumental permite combinar dados de séries temporais (time series) com dados de corte transversal (cross-section). De acordo com Kennedy (2009), os dados em painel possuem as seguintes vantagens:

1) Podem ser utilizados para estudar a heterogeneidade das unidades de corte transversal e até mesmo para verificar o impacto do tempo no comportamento das unidades micro (corte transversal). As vezes isso é descrito como o problema da variável omitida, que é solucionado pelo método de dados em painel;

2) Reduzem a possibilidade de multicolinearidade, devido à variabilidade entre as unidades micro. A estimativa tende a ser mais eficiente;

3) Permitem a análise de questões que não podem ser estudadas apenas por dados de séries temporais ou cross-section. Por exemplo, analisar o comportamento de uma empresa (indivíduo) ao longo do tempo; e,

4) Permitem fazer uma análise dinâmica de dados individuais, o que não é possível utilizando apenas dados de corte transversal.

Conforme Hill, Judge e Griffiths (2010), o método de dados em painel pode ser representado pela equação 17 :

$$
Y_{i t}=\beta_{1 i}+\beta_{2 i} X_{2 i}+\beta_{3 i} X_{3 i}+\ldots+\beta_{k i t} X_{k i t}+u_{i},
$$

em que $Y_{i t}$ é a variável dependente; $X_{i t}$, variáveis explicativas; $\beta_{1}$, intercepto; 
$\beta_{2}, \ldots, \beta_{k}$, coeficientes parciais de inclinação; $u_{i t}$, termo de perturbação estocástico; $i$, diferentes indivíduos; e, $t$, período de tempo considerado. Em forma matricial a equação 17 pode ser expressa por:

$$
\begin{aligned}
& {\left[\begin{array}{c}
Y_{i 1} \\
Y_{i 2} \\
\vdots \\
Y_{T T}
\end{array}\right]=\left[\begin{array}{ccccc}
1 & X_{1 i 1} & X_{2 i 1} & \cdots & X_{k 1} \\
1 & X_{1 i 2} & X_{2 i 2} & \cdots & X_{k 2} \\
\vdots & \vdots & \vdots & \vdots & \vdots \\
1 & X_{1 T} & X_{2 T T} & \cdots & X_{K i T}
\end{array}\right]\left[\begin{array}{c}
\beta_{1 i} \\
\beta_{2 i} \\
\vdots \\
\beta_{K i T}
\end{array}\right]+\left[\begin{array}{c}
u_{i 1} \\
u_{i 2} \\
\vdots \\
u_{i T}
\end{array}\right] \text {, }} \\
& y=X \quad \beta+u, \\
& T \times 1 \quad K \times T \quad K \times 1 \quad T \times 1,
\end{aligned}
$$

em que $y$ é o vetor coluna $T \times 1$ de observações sobre a variável dependente $Y$; $X$, matriz $K \times T$, representando as variáveis explicativas do modelo, sendo que a primeira coluna de $1 s$ expressa o termo de intercepto; $\beta$, vetor coluna $K \times 1$ dos parâmetros desconhecidos $\beta_{1}, \beta_{2}, \ldots, \beta_{K}$; e, $u$, vetor coluna $T \times 1$ das $T$ perturbações $u$.

Nota-se, pela equação 18, que nesse modelo geral os interceptos e os parâmetros podem diferir entre os indivíduos e de período para período de tempo. Dessa forma, o modelo não pode ser estimado em sua forma original, uma vez que existem mais parâmetros desconhecidos do que observações (HILL, JUDGE e GRIFFITHS, 2010). Assim, hipóteses simplificadoras devem ser tomadas de forma a estimar os parâmetros desconhecidos. Entre os modelos que podem ser utilizados estão: modelo de efeitos fixos e modelo de efeitos aleatórios (ou modelo de componentes de erro) $)^{9}$, apresentados a seguir.

\subsection{Modelo de efeitos fixos}

A ideia no modelo de efeitos fixos é controlar os efeitos das variáveis que foram omitidas do modelo e que podem ser diferentes entre os indivíduos, mas constantes no tempo. Para capturar a diferença entre as diferentes unidades de corte transversal toma-se o coeficiente de intercepto como constante ao longo do tempo e variando entre os indivíduos (unidades micro). No caso dos coeficientes angulares, esses são considerados constantes entre as unidades micro e ao longo do tempo.

Assim, de acordo com Hill, Judge e Griffiths (2010), as suposições a serem feitas sobre o modelo são as seguintes:

9 Outros métodos de dados em painel podem ser consultados em consultar Wooldridge (2002) e Wooldridge (2006), tais como: método de mínimos quadrados ordinários agrupados, método de primeira diferença, entre outros. 


$$
\beta_{1 \dot{t}}=\beta_{1 i} ; \beta_{2 i}=\beta_{2} ; \beta_{3 i}=\beta_{3} ; \ldots ; \beta_{k i t}=\beta_{k} .
$$

O modelo de efeitos fixos é representado, então, por:

$$
Y_{i t}=\beta_{1 i}+\beta_{2} X_{2 i}+\beta_{3} X_{3 i}+\ldots+\beta_{k} X_{k i t}+u_{i},
$$

que em sua forma matricial fica expresso da seguinte maneira:

$$
\left[\begin{array}{c}
Y_{i 1} \\
Y_{i 2} \\
\vdots \\
Y_{i T}
\end{array}\right]=\left[\begin{array}{ccccc}
1 & X_{1 i 1} & X_{2 i 1} & \cdots & X_{k 1} \\
1 & X_{1 i 2} & X_{2 i 2} & \cdots & X_{k 2} \\
\vdots & \vdots & \vdots & \vdots & \vdots \\
1 & X_{1 T T} & X_{2 i T} & \cdots & X_{K i T}
\end{array}\right]\left[\begin{array}{c}
\beta_{1 i} \\
\beta_{2} \\
\vdots \\
\beta_{K}
\end{array}\right]+\left[\begin{array}{c}
u_{i 1} \\
u_{i 2} \\
\vdots \\
u_{i T}
\end{array}\right],
$$

em que $\beta_{1 i}$ refere-se aos coeficientes de intercepto, a serem estimados para cada indivíduo.

Segundo Greene (2002), para diferenciar o intercepto de um indivíduo para o outro, faz-se a utilização de variáveis dummies (variáveis binárias) no modelo a ser estimado. Stock e Watson (2004) salientam que as variáveis binárias refletem todas as variáveis omitidas que diferem de um indivíduo para outro, mas que são constantes ao longo do tempo.

O modelo com variáveis binárias pode ser representando como:

$$
Y_{i t}=\beta_{1}+\beta_{2} X_{2 i}+\beta_{3} X_{3 i}+\ldots+\beta_{k} X_{k i t}+\alpha_{2} D_{2 i}+\alpha_{3} D_{3 i}+\ldots+\alpha_{n} D_{\dot{i}}+u_{i},
$$

em que $D_{i n}$ expressa a variável binária para cada unidade micro (indivíduo), sendo igual a um quando $i=n$ e, zero, caso contrário. Nota-se que são introduzidas $n-1$ variáveis binárias, a fim de evitar o problema da multicolinearidade. Nesse caso, para $i=1$, o intercepto é dado por $\beta_{1}$. Para $i>1$ o intercepto é representado por $\beta_{1}+\alpha_{i}$.

Caso os erros sigam distribuição normal, variância constante (homoscedasticidade) e sejam não autocorrelacionados, a equação 22 pode ser estimada por Mínimos Quadrado Ordinários (MQO). Vale frisar aqui que as estimativas por MQO são não tendenciosas e consistentes.

Para Wooldridge (2006), o modelo com variáveis binárias produz os mesmos resultados que o modelo de efeitos fixos. Porém, a inclusão de variáveis dummies no modelo eleva o número de parâmetros, o que reduz os graus de liberdade. Dessa 
forma, Hill, Judge e Griffiths (2010) sugerem a realização de um teste para verificar se realmente os interceptos são distintos entre os indivíduos. As hipóteses a serem testadas são as seguintes:

$$
H_{0}: \beta_{1}=\beta_{1}=\ldots=\beta_{1 k}
$$

$H_{1}$ : os interceptos $\beta_{1 i}$ não são todos iguais,

a estatística de teste utilizada é a $F$ (teste $F$ ). A rejeição da hipótese nula demonstra que os interceptos não são iguais para todos os indivíduos

Kennedy (2009) afirma que o modelo de efeitos fixos deve ser utilizado quando: a) as variáveis omitidas (o intercepto) são correlacionadas com as variáveis explicativas do modelo considerado; e, b) os dados referem-se a toda população (amostra abrange todos os indivíduos de uma população) e deseja-se fazer inferências sobre os indivíduos.

\subsection{Modelo de efeitos aleatórios}

No modelo de efeitos aleatórios a ideia continua sendo modelar diferenças no comportamento dos indivíduos, fazendo com que cada unidade micro tenha um intercepto diferente, variando entre indivíduos, mas não ao longo do tempo. Os coeficientes angulares são constantes entre todas as unidades de corte transversal e ao longo do tempo.

O que difere o modelo de efeitos aleatórios do modelo de efeitos fixos é que o modelo de componentes de erro considera o intercepto como uma variável aleatória. "Esse modelo é conveniente se os indivíduos (unidades de corte transversal) que aparecem na amostra são escolhidos aleatoriamente e considerados representativos de uma população maior de indivíduos” (HILL, JUDGE e GRIFFITHS, 2010, p. 416).

Para expressar o modelo de efeitos aleatórios, considera-se a equação 24 :

$$
Y_{i t}=\beta_{1 i}+\beta_{2} X_{2 i}+\beta_{3} X_{3 i}+\ldots+\beta_{k} X_{k i t}+u_{i} .
$$

Toma-se, então, $\beta_{1 i}$ como sendo aleatório e modelado da forma a seguir:

$$
\beta_{1 i}=\bar{\beta}_{1}+e_{i}, \operatorname{com} i=1, \ldots, n,
$$

em que $\bar{\beta}_{1}$ é um parâmetro desconhecido que representa o intercepto populacional médio; e, $e_{i}$, erro aleatório não observável que expressa as diferenças no comportamento dos indivíduos. Admiti-se que os $e_{i}$ sejam independentes uns dos outros e dos $u_{i t}$. Além disso, $E\left(e_{i}\right)=0$ e $\operatorname{var}\left(e_{i}\right)=\sigma_{e}^{2}$. No mais $e_{i}$ são não correlacionados com as variáveis explicativas do modelo em todos os períodos de tempo. 
Baseando-se nas equações 24 e 25, o modelo geral de efeitos aleatórios pode ser representado pela equação 26 :

$$
Y_{i t}=\bar{\beta}_{1}+\beta_{2} X_{2 i}+\beta_{3} X_{3 i}+\ldots+\beta_{k} X_{k i t}+v_{i},
$$

em que $v_{i t}=u_{i}+e_{i}$. O nome modelo de componentes de erro provém do fato de o termo do erro $v_{i t}$ ser composto por dois componentes: o erro global $u_{i t}$ e o erro específico individual $e_{i}$. O termo do erro $e_{i}$ representa as diferenças entre indivíduos, variando de acordo com as unidades micro, e sendo constante ao longo do tempo.

A representação matricial do modelo de efeitos aleatórios é dada por:

$$
\left[\begin{array}{c}
Y_{i 1} \\
Y_{i 2} \\
\vdots \\
Y_{T T}
\end{array}\right]=\left[\begin{array}{ccccc}
1 & X_{1 i 1} & X_{2 i 1} & \cdots & X_{k 1} \\
1 & X_{1 i 2} & X_{2 i 2} & \cdots & X_{k 2} \\
\vdots & \vdots & \vdots & \vdots & \vdots \\
1 & X_{1 T T} & X_{2 T T} & \cdots & X_{K i T}
\end{array}\right]\left[\begin{array}{c}
\bar{\beta}_{1} \\
\beta_{2} \\
\vdots \\
\beta_{K}
\end{array}\right]+\left[\begin{array}{c}
v_{i 1} \\
v_{i 2} \\
\vdots \\
v_{i T}
\end{array}\right] .
$$

Conforme Hill, Judge e Griffiths (2010), as propriedades do novo termo de perturbação estocástica $\left(v_{i t}\right)$ são dadas por: i) $E\left(v_{i t}\right)=0$. O termo de erro $v_{i t}$ tem média zero; ii) $\operatorname{var}\left(v_{i t}\right)=\sigma_{e}^{2}+\sigma_{u}^{2}$. O que significa que $v_{i t}$ tem variância constante (homoscedasticidade); iii) $\operatorname{cov}\left(v_{\dot{t}}, v_{\dot{b}}\right)=\sigma_{e}^{2} ; \forall(t \neq s)$. Os erros do mesmo indivíduo em diferentes períodos de tempo são correlacionados; e, iv $) \operatorname{cov}\left(v_{\dot{t}}, v_{\dot{s}}\right)=0$; $\forall(i \neq j)$. Os erros de diferentes unidades individuais no mesmo período são não correlacionados.

Uma vez que os erros do mesmo indivíduo em diferentes períodos de tempo são correlacionados, a técnica de $\mathrm{MQO}$ não é mais adequada. Para o modelo de efeitos aleatórios o método mais adequado é o método de MQG ${ }^{10}$. De acordo com Wooldridge (2006), sob algumas hipóteses, esse modelo traz estimadores não viesados, consistentes e que seguem assintoticamente distribuição normal.

\subsection{Teste de Hausman}

No que se refere aos mecanismos para decidir entre a escolha do modelo de efeitos fixos e do modelo de efeitos aleatórios, uma das técnicas é o teste de Hausman (1978). A estatística de teste de teste é obtida a partir da equação 28:

10 Para detalhes do método de MQG consultar Wooldridge (2002, capítulo 10) e Wooldridge (2006, capítulo 14). 


$$
W=\left(\hat{\beta}_{E}-\hat{\beta}_{H}\right)\left[\operatorname{var}\left(\hat{\beta}_{E}\right)-\operatorname{var}\left(\hat{\beta}_{B}\right)\right]^{-1}\left(\hat{\beta}_{E}-\hat{\beta}_{B}\right) \sim \chi_{k}^{2},
$$

em que $\hat{\beta}_{\mathbb{E}}$ refere-se ao vetor de coeficientes estimados pelo modelo de efeitos fixos; $\hat{\beta}_{B}$, vetor de coeficiente estimados pelo modelo de efeitos aleatórios. No mais, o teste de Hausman segue distribuição qui-quadrado com $k$ graus de liberdade, sendo $k$ o número de regressores, exceto o intercepto.

A hipótese nula a ser testada é que os estimadores de efeitos fixos não são substancialmente diferentes dos estimadores de efeitos aleatórios. Ou, que o termo do erro $e_{i}$ não é correlacionado com as variáveis explicativas do modelo. Se a hipótese nula não for rejeitada, conclui-se que o modelo de efeitos aleatórios é o mais adequado. Caso contrário, opta-se pelo modelo de efeitos fixos.

\section{Resultados}

\subsection{Apresentação das variáveis}

Os dados deste estudo foram do tipo dados em painel. As variáveis estão descritas na tabela 1. Conforme mencionado anteriormente, a análise compreendeu o período de 2005 a 2012, abrangendo os 78 municípios do Espírito Santo. Os dados foram obtidos do Instituto Brasileiro de Geografia e Estatística (IBGE), da Secretaria do Tesouro Nacional (STN) e da Federação das Indústrias do Estado do Rio de Janeiro (FIRJAN). Quando necessário, as variáveis foram deflacionadas pelo Índice de Preços ao Consumidor Amplo - IPCA.

Destaca-se aqui, que, também, tentou-se a utilização das seguintes variáveis dependentes: a) despesa de apoio à produção, composta por despesas com indústria, comércio e serviços; e, b) despesa de infraestrutura, referente a despesas com comunicação, energia e recursos naturais. No entanto, como alguns municípios do Espírito Santo, em geral, realizam poucos gastos com estes serviços ou não realizam despesas com os mesmos, optou-se por não trabalhar com essas variáveis. No mais, algumas variáveis sugeridas pela literatura não foram utilizadas devido à indisponibilidade de dados para o período considerado. 
Tabela 1 - Variáveis utilizadas

\begin{tabular}{|c|c|}
\hline Variáveis dependentes & Descrição \\
\hline Despesa global (DESPORC) & Despesa orçamentária total de cada município. \\
\hline Despesa de gabinete (DESPGAB) & Despesa com legislativo, judiciário e planejamento. \\
\hline $\begin{array}{c}\text { Despesa com agricultura } \\
\text { (DESPAGR) }\end{array}$ & Despesa com agricultura. \\
\hline $\begin{array}{c}\text { Despesa com educação e cultura } \\
\text { (DESPEDUC) }\end{array}$ & Despesa com educação e cultura. \\
\hline $\begin{array}{l}\text { Despesa de seguridade social } \\
\text { (DESPSEGUR) }\end{array}$ & Despesa com saúde, previdência e assistência social. \\
\hline Variáveis explicativas & Descrição \\
\hline $\begin{array}{l}\text { Parcela do imposto ou tax-price } \\
\text { (TXPRICE) }\end{array}$ & $\begin{array}{l}\text { Razão entre a receita tributária per-capita local e o total de } \\
\text { receita orçamentária de cada município. Uma medida de } \\
\text { esforço fiscal. }\end{array}$ \\
\hline Renda média ampliada (RENDA) & $\begin{array}{l}\text { Soma entre o PIR per capita de cada município e produto da } \\
\text { multiplicação do tax-price pelo montante das transferências } \\
\text { intergovernamentais recebidas por cada município. }\end{array}$ \\
\hline População do município (POP) & Número de habitantes de cada município. \\
\hline IFDM & $\begin{array}{l}\text { Índice da FIRJAN que engloba estatísticas de emprego, } \\
\text { renda, educação e saúde. }\end{array}$ \\
\hline $\begin{array}{c}\text { Transferências intergovernamen- } \\
\text { tais (TRANSF) }\end{array}$ & $\begin{array}{l}\text { Transferências governamentais provenientes dos governos } \\
\text { federal e estadual. }\end{array}$ \\
\hline $\begin{array}{l}\text { Distância da capital } \\
\text { (DISTCAPITAL) }\end{array}$ & $\begin{array}{l}\text { Distância, em linha reta, do município à capital do Estado, } \\
\text { em Km. }\end{array}$ \\
\hline $\begin{array}{l}\text { Partidos políticos (PDT, PFL/DEM, } \\
\text { PHS, PL, PMDB, PMN, PP, PPS, } \\
\text { PR, PRB, PRTB, PSB, PSC, PSDB, } \\
\text { PSDC, PT, PT do B, PTB e PV }\end{array}$ & $\begin{array}{l}\text { Partido político do prefeito. Variável categórica, sendo } \\
\text { representada por meio de dummies. Nesse caso, quando o } \\
\text { prefeito de um município era do partido "Z", por exemplo, } \\
\text { a variável foi igual a um; e, caso contrário, foi igual a zero. }\end{array}$ \\
\hline
\end{tabular}

\subsection{Estatísticas descritivas}

A tabela 2 resume as estatísticas descritivas das variáveis utilizadas no estudo. As estatísticas consideram o período com um todo (2005 a 2012) e os 78 municípios capixabas. Nota-se que, a despesa média orçamentária total foi de R $\$$ 58.439.996,00,00. A maior despesa média, por função, faz-se para as despesas com educação e cultura, seguida das despesas com seguridade social. Verifica-se, também, que há um grande volume de recursos empenhados com despesas de gabinete, 
sendo que essas não necessariamente contribuem para o desenvolvimento dos setores produtivos e melhoria do bem-estar social, uma vez que são despesas meramente administrativas.

Outro ponto relevante é que o montante de recursos destinados às despesas com agricultura não é expressivo, com uma média de gastos da ordem de R\$ $859.519,30$. Nesse caso, vale a ressalva de que alguns municípios, por suas características geográficas, praticamente não têm despesas com agricultura (é o caso de Vitória, por exemplo), o que leva a média de gastos para baixo. Entretanto, dado que o PIB agropecuária ainda representa, em média, cerca de 25\% do PIB total dos municípios do estado, e que o setor, ainda, é o mais representativo no PIB total (alguns municípios possuem cerca de 50\% de seu PIB total representado pelo PIB agropecuário) para vários municípios, especialmente os do interior, esperava-se investimentos maiores.

Tabela 2 - Estatísticas descritivas das variáveis

\begin{tabular}{l|c|c|c|c|c}
\hline \multicolumn{1}{c|}{ Variável } & Média & Mediana & Desvio padrão & Máximo & Mínimo \\
\hline DESPORC & $58.439 .996,00$ & $22.977 .331,00$ & $120.000 .000,00$ & $1.020 .000 .000,00$ & $6.513 .933,00$ \\
\hline DESPGAB & $10.915 .376,00$ & $4.929 .762,00$ & $18.744 .854,00$ & $140.000 .000,00$ & $1.016 .186,00$ \\
\hline DESPAGR & $859.519,30$ & $740.565,20$ & $808.338,30$ & $6.906 .012,00$ & 0,00 \\
\hline DESPEDUC & $16.979 .439,00$ & $7.163 .817,00$ & $31.141 .141,00$ & $229.000 .000,00$ & $1.317 .416,00$ \\
\hline DESPSEGUR & $14.105 .267,00$ & $5.892 .398,00$ & $29.902 .418,00$ & $285.000 .000,00$ & $1.060 .387,00$ \\
\hline TXPRICE & 0,00000305 & 0,00000258 & 0,00000212 & 0,00001670 & 0,00000041 \\
\hline RENDA & $12.256,64$ & $7.997,45$ & $23.223,26$ & $358.340,60$ & 125,36 \\
\hline POP & $44.532,97$ & $17.878,00$ & $82.723,01$ & $424.948,00$ & $4.471,00$ \\
\hline IFDM & 0,67 & 0,67 & 0,08 & 0,86 & 0,46 \\
\hline TRANSF & $44.538 .345,00$ & $20.160 .142,00$ & $76.329 .219,00$ & $596.000 .000,00$ & $6.361 .611,00$ \\
\hline DISTCAPITAL & 114,52 & 113,39 & 60,80 & 254,17 & 0,00 \\
\hline \multicolumn{7}{|c|}{ Fonte: elaborado pelo autor a partir dos dados da pesquisa. }
\end{tabular}

Destaca-se o fato de a média de transferências intergovernamentais ser relativamente próxima à média das despesas orçamentárias, refletindo certa dependência dos municípios capixabas a estas transferências. Por fim, importante mencionar a grande variabilidade dos dados em torno das médias de cada variável. Isto pode ser reflexo das disparidades existentes entre os municípios do estado, especialmente, entre os da região metropolitana e os do interior, sejam elas políticas, populacionais, geográficas, sociais, etc. 


\subsection{Estimativas econométricas}

Neste item são apresentados os resultados referentes às estimativas realizadas a partir do método de dados em painel. Em todos dos casos, as regressões foram estimadas na forma duplo-logarítmica, conforme equação 15. O teste de Jarque-Bera (JB) demonstrou, nas estimativas por MQO com efeitos fixos, que os erros não possuem distribuição normal. Wooldridge (2002) salienta que o método de MQG diminui os impactos da não normalidade dos resíduos sobre o modelo estimado e, nesse caso, é possível aceitar a não normalidade dos resíduos, mesmo ela persistindo após a estimação da regressão desejada. Assim, nas estimativas com efeitos fixos adotou-se o método de MQG. Também, para todos os modelos, com o intuito de obter erros padrões robustos, foi utilizado o método de covariância do coeficiente (coef covariance method) White Cross-Section.

Os resultados da tabela 3 consideram como variável dependente a despesa total dos municípios (DESPORC). $\mathrm{O}$ teste $\mathrm{F}$ rejeitou a hipótese de que não há variabilidade no termo de intercepto, logo o método de dados em painel é o mais adequado. Além disso, ao nível de significância de $10 \%$ o teste de Hausman demonstrou que se deve rejeitar a hipótese nula de que o modelo de efeitos aleatórios apresenta estimadores mais consistentes e eficientes do que o modelo de efeitos fixos ${ }^{11}$.

Nota-se que, a variável DISTCAPITAL e os partidos políticos PDT, PL, PSDB e PTB $^{12}$ não foram significativos ao nível de 10\%. As demais variáveis e partidos políticos foram significativos aos níveis de $1 \%$ ou $5 \%$. A variável TXPRICE apresentou sinal negativo, coerente com a teoria econômica, isto é, à medida que o esforço fiscal aumentou (elevação da carga tributária municipal), a demanda por serviços públicos locais diminuiu. Nesse caso, no período de estudo, para cada aumento de $1 \%$ no esforço-fiscal ocorreu uma elevação de $0,059 \%$ na demanda por bens públicos, nos municípios do Espírito Santo, demonstrando uma demanda inelástica. Vale destacar que grande parte dos serviços públicos é essencial para população, o que pode sinalizar que, mesmo com o aumento do preço do bem público, os indivíduos reduzem pouco o consumo do mesmo.

11 Vale mencionar que o coeficiente de determinação para modelos de efeitos fixos tende a ser elevado, devido ao grande número de variáveis explicativas, advindas da inclusão de variáveis dummies para diferenciar os indivíduos.

12 No que se refere às estimativas para o impacto dos partidos políticos, destaca-se que, dado o grande número de partidos (19 no total) que governou algum município do Espírito Espírito, no período de estudo, optou-se por colocar os partidos que tiveram prefeito em apenas um município, em uma única variável dummy. Esses partidos foram: PHS, PRB, PRTB, PSC, PSDC e PV. Para evitar o problema de multicolinearidade, tais partidos foram representados pelo termo de intercepto nas estimativas. Essa observação é válida para as estimativas de todas as informações. 
Tabela 3 - Determinantes da despesa global (DESPORC)

\begin{tabular}{|c|c|c|c|c|}
\hline Variáveis & Coeficientes & Erro-padrão & Valor $\mathrm{t}$ & P-valor \\
\hline $\mathrm{C}$ & $-0,7939^{\text {ns }}$ & 2,4410 & $-0,3252$ & 0,7451 \\
\hline LOG(TXPRICE) & $-0,0549 * * *$ & 0,0177 & $-3,0976$ & 0,0021 \\
\hline LOG(RENDA) & $0,0051 * *$ & 0,0026 & 1,9364 & 0,0534 \\
\hline LOG(POP) & $0,1573 * \cdots$ & 0,0490 & 3,2117 & 0,0014 \\
\hline LOG(IFDM) & $0,3761 \% * \%$ & 0,0926 & 4,0639 & 0,0001 \\
\hline LOG(TRANSF) & $0,8192 * * *$ & 0,0385 & 21,2659 & 0,0000 \\
\hline LOG(DISTCAPITAL) & $0,7119^{\mathrm{ns}}$ & 0,5398 & 1,3187 & 0,1878 \\
\hline DEM/PFL & $0,0761 * * * *$ & 0,0154 & 4,9488 & 0,0000 \\
\hline PDT & $0,0092^{\text {ns }}$ & 0,0345 & 0,2658 & 0,7905 \\
\hline PL & $-0,1202^{\mathrm{ns}}$ & 0,0792 & $-1,5168$ & 0,1299 \\
\hline PMDB & $0,0653 * * *$ & 0,0196 & 3,3361 & 0,0009 \\
\hline PMN & $0,1218 * \cdots *$ & 0,0223 & 5,4665 & 0,0000 \\
\hline PP & $0,0579 * * *$ & 0,0157 & 3,6997 & 0,0002 \\
\hline PPS & $0,0427 * * * *$ & 0,0100 & 4,2924 & 0,0000 \\
\hline PR & $0,1113 * * *$ & 0,0228 & 4,8909 & 0,0000 \\
\hline PSB & $0,0614 * * *$ & 0,0139 & 4,4041 & 0,0000 \\
\hline PSDB & $0,0469 * * *$ & 0,0154 & 3,0369 & 0,0025 \\
\hline PT & $0,0522 * \%$ & 0,0245 & 2,1343 & 0,0333 \\
\hline PTB & $0,0039^{\text {ns }}$ & 0,0249 & 0,1555 & 0,8765 \\
\hline PTDOB & $0,1710 * * *$ & 0,0329 & 5,1906 & 0,0000 \\
\hline PAR. CONGESTIONAMENTO & \multicolumn{4}{|c|}{0,1024} \\
\hline
\end{tabular}

$$
\begin{gathered}
R^{2}=0,9942 \text { Teste } \mathrm{F}(77,527)=2,2429[0,0000] \\
\text { Hausman }=50,2218[0,0001]
\end{gathered}
$$

Fonte: elaborado pelo autor a partir dos dados da pesquisa.

Nota: 1$) * *$ Significativo a $1 \%$; * Significativo a $5 \%$; ${ }^{\text {ns }}$ Não significativo a $10 \% ; 2$ ) L = Indica que as variáveis estão expressas em logaritmos; 3 ) Utilizou-se o método de MQG (cross-section weights), com efeitos fixos.

No caso da elasticidade-renda (RENDA), essa foi positiva e inferior à unidade, demonstrando que os bens públicos foram de caráter normal ou essencial para a população dos municípios do Espírito Santo, embora não possam ser caracterizados como bens superiores. $\mathrm{O}$ aumento de $1 \%$ na renda provocou um leve crescimento de $0,0051 \%$ na demanda por bens públicos locais. Dadas as características da elasticidade-preço da demanda e da elasticidade renda, e baseando na teoria microeconômica, pode-se caracterizar os bens públicos nos municípios do Espírito Santo como de primeira necessidade para a população, o que revela a importância de políticas públicas bem elaboradas para essas localidades. 
Quanto à variável POP, para cada aumento de 1\% na mesma teve-se um crescimento de $0,1573 \%$ nas despesas totais dos municípios. Isso era esperado, uma vez que o aumento da população por si só tende a elevar a demanda por bens oferecidos pelo governo, tais como: educação, saúde, saneamento, entre outros. Em relação à variável IFDM, o coeficiente positivo releva que, no período em questão, o aumento dessa variável aumentou a demanda por bens públicos. Esse resultado foi expressivo, mas deve-se levar em conta que o IFDM abrange indicadores como emprego, renda, educação e saúde. No mais, isso pode ser devido ao fato de que, a medida que a população dos municípios capixabas alcança melhores condições de vida, as exigências aumentam, e as comunidades passam a demandar mais bens públicos e com maior qualidade.

O maior impacto sobre as despesas totais foi da variável TRANSF. Nesse caso, cada variação de $1 \%$ no montante de transferências intergovernamentais acarretou uma variação de 0,8192\% nas despesas públicas dos municípios do Espírito Santo. Importante mencionar aqui o chamado flypaper effect, diagnosticado quando o efeito das transferências intergovernamentais sobre as despesas públicas é maior do que o efeito de aumentos equivalentes na renda dos indivíduos contribuintes, sendo que esse fenômeno ocorreu para os municípios capixabas, no período de análise. Isso, em tese, vai contra as previsões do modelo do eleitor mediano mais tradicional, que diz que os impactos das transferências intergovernamentais e da renda deveriam ser os mesmos, dada uma variação equivalente em ambas as variáveis. De acordo Fisher (1982) e Wycoff (1991), apud Cossio e Carvalho (2001), nesse caso, as transferências intergovernamentais tendem a concentrar-se nas unidades receptoras (governos locais). Assim, esses governos tendem a expandir seus gastos, ao invés de redistribuir tais transferências aos contribuintes, através, por exemplo, de redução de impostos.

Entre as várias análises que poderiam ser realizadas em relação aos impactos dos partidos políticos nas despesas orçamentárias, cabe mencionar o fato de que os efeitos dos partidos PT e PSDB foram significativos e positivos. No entanto, a diferença entre os coeficientes estimados desses partidos não foi muito elevada. Isso é uma questão interessante, pois, de certa forma, esperava-se efeitos muito maiores do PT do que do PSDB, uma vez que o PT é visto com um partido que apoia mais fortemente a participação do governo na provisão de serviços.

$\mathrm{O}$ coeficiente de congestionamento foi estimado conforme equação 16. Esse refere-se ao grau de publicização dos bens públicos municipais. $\mathrm{O}$ valor encontrado $(0,1024)$ está bem abaixo daqueles encontrados por Mendes (2005) e Barcelos (2007) para os municípios brasileiros, evidenciando que, em média, existem grandes economias de escala a serem exploradas pelos municípios do Espírito Santo. Dessa forma, os bens públicos dos municípios capixabas podem ser classificados como semipúblicos ou semiprivados. Esse alto grau de publicização pode ser explicado pela pequena extensão territorial da maioria dos municípios do Espírito Santo. Conforme Barcelos (2007, p. 73), os municípios menores não conseguem otimizar 
escalas de produção e consumo. Logo, ficam submetidos a elevados custos médios. Assim, como o subconsumo leva a um menor efeito congestionamento, a adição de novos consumidores reduziria os custos marginais (tax-price) do setor público. Resultado semelhante foi encontrado por MacMillan et al. (1981) ao estudar pequenas comunidades urbanas do Canadá. Já Borcherding e Deacon (1972), Bergstrom e Goodman (1973) encontraram estimativas próximas ou maiores que a unidade.

Os resultados quando considerada como variável dependente as despesas dos municípios com gabinete (DESPGAB) são demonstrados na tabela 4. Os testes F e de Hausman (nível de 10\%) determinaram a utilização do modelo de efeitos fixos. As variáveis RENDA e IFDM não foram significativas ao nível de 10\%. Observa-se que, com exceção dos partidos políticos PTB e PTDOB, as demais variáveis e partidos foram significativos estatisticamente. A variável TXPRICE apresentou sinal contrário ao esperado e inelasticidade. Vale destacar que, as despesas de gabinete são meramente administrativas e formadas pelos gastos com legislativo, judiciário e planejamento, que não estão necessariamente ligadas ao setor produtivo ou ao bem-estar social. Assim, essa demanda inelástica pode indicar um falso entendimento da população dos municípios do estado, a não reduzir significantemente a demanda por serviços de gabinete quando o preço dos mesmos se eleva. Vale frisar que, no ano de 2012, por exemplo, para cerca de 78\% dos municípios do Espírito Santo, as despesas de gabinete representam mais do que 20\% das despesas totais.

No que se refere às variáveis renda e população, essas apresentaram sinais positivos e coerentes com o esperado. Especificamente, no que tange à população, supõe-se que comunidades maiores gerem maiores dispêndios com a função gabinete, assim como no caso de cidades mais urbanizadas. O coeficiente da variável TRANSF mostrou-se significativo, revelando que, para cada aumento de $1 \%$ nas transferências intergovernamentais, ocorreu uma elevação de 0,4346\% nas despesas de gabinete dos municípios. Dessa forma, parece que as transferências intergovernamentais tenderam a reforçar as despesas de gabinete, ressaltando que não necessariamente essas despesas irão contribuir para o crescimento do setor produtivo e o maior bem-estar dos munícipes. A variável distância da capital teve coeficiente negativo. Localidades mais afastadas da capital tendem a gastar menos com despesas de gabinete. Importante destacar que, no caso dos partidos políticos, praticamente todos os coeficientes foram positivos. Isso significa que, independentemente do partido, as despesas de gabinete tendem a ser elevadas. No mais, o parâmetro de congestionamento foi igual a 0,3604. 
Tabela 4 - Determinantes das despesas: função gabinete (DESPGAB)

\begin{tabular}{|c|c|c|c|c|}
\hline Variáveis & Coeficientes & Erro-padrão & Valor $\mathrm{t}$ & P-valor \\
\hline $\mathrm{C}$ & $20,6122 * * *$ & 4,5309 & 4,5493 & 0,0000 \\
\hline LOG(TXPRICE) & $0,1205 * \cdots$ & 0,0185 & 6,5084 & 0,0000 \\
\hline LOG(RENDA) & $0,0248 * * *$ & 0,0053 & 4,6989 & 0,0000 \\
\hline LOG(POP) & $0,2851 * *$ & 0,1225 & 2,3279 & 0,0203 \\
\hline LOG(IFDM) & $0,3551 * * *$ & 0,0954 & 3,7213 & 0,0002 \\
\hline LOG(TRANSF) & $0,4346 * * * *$ & 0,0181 & 23,9768 & 0,0000 \\
\hline LOG(DISTCAPITAL) & $-3,0847 * \cdots *$ & 1,0723 & $-2,8766$ & 0,0042 \\
\hline DEM/PFL & $0,1078 \% *$ & 0,0432 & 2,4968 & 0,0128 \\
\hline PDT & $0,1460 \% * *$ & 0,0356 & 4,1030 & 0,0000 \\
\hline PL & $-0,1271 * * \%$ & 0,0357 & $-3,5583$ & 0,0004 \\
\hline PMDB & $0,1178 * * *$ & 0,0432 & 2,7243 & 0,0067 \\
\hline PMN & $0,1715 \%$ & 0,0868 & 1,9750 & 0,0488 \\
\hline $\mathrm{PP}$ & $0,2973 * * *$ & 0,0446 & 6,6695 & 0,0000 \\
\hline PPS & $0,1502 * * *$ & 0,0433 & 3,4679 & 0,0006 \\
\hline PR & $0,5008 * \cdots *$ & 0,0968 & 5,1717 & 0,0000 \\
\hline PSB & $0,1000 * \% *$ & 0,0248 & 4,0288 & 0,0001 \\
\hline PSDB & $0,1041 \% * \%$ & 0,0215 & 4,8451 & 0,0000 \\
\hline PT & $0,1621 * \% *$ & 0,0413 & 3,9214 & 0,0001 \\
\hline PTB & $-0,0384^{\mathrm{ns}}$ & 0,0467 & $-0,8213$ & 0,4119 \\
\hline PTDOB & $0,0601^{\mathrm{ns}}$ & 0,0611 & 0,9841 & 0,3255 \\
\hline PAR. CONGESTIONAMENTO & \multicolumn{4}{|c|}{0,3604} \\
\hline
\end{tabular}

$$
\begin{gathered}
R^{2}=0,5485 \quad \text { Teste } \mathrm{F}(77,527)=12,7184[0,0000] \\
\text { Hausman }=29,9887[0,0662]
\end{gathered}
$$

Fonte: elaborado pelo autor a partir dos dados da pesquisa.

Nota: 1$) * * *$ Significativo a $1 \%$; *\%* significativo a $5 \%$; ${ }^{\text {ns }}$ Não significativo a $10 \% ; 2$ ) L = Indica que as variáveis estão expressas em logaritmos; 3) Utilizou-se o método de MQG (cross-section weights), com efeitos fixos.

A tabela 5 demonstra as estimativas quando consideradas as despesas dos municípios com a agricultura. Tomando-se como base os testes $\mathrm{F}$ e de Hausman (ao nível de significância de 10\%), utilizou-se o modelo de efeitos fixos. Nota-se que as variáveis RENDA, IFDM e DISTCAPITAL não foram significativas, assim como os partidos PDT, PL, PMDB, PMN, PPS, PSB e PTB. As demais variáveis e os outros partidos foram estatisticamente significantes.

No que se refere a variável TXPRICE, seu coeficiente revela que o aumento de $1 \%$ no preço do bem público levou a uma redução de $0,3147 \%$ demanda por 
bens públicos voltados a agricultura, sendo que a elasticidade-preço da demanda foi inelástica. Em geral, o território do Espírito Santo é formado por pequenas propriedades, em muitos casos baseadas na agricultura familiar. Dessa forma, qualquer aumento no esforço fiscal pode reduzir a demanda por bens públicos destinados à agricultura. Assim, em municípios com menor esforço fiscal são maiores as despesas com agricultura. Importante ressaltar que os municípios capixabas destinam um baixo percentual de suas despesas totais para as despesas com agricultura.

A variável população teve sinal negativo. Isso pode ser devido ao fato de que, no caso dos municípios do Espírito Santo, a agricultura está mais concentrada nos municípios do interior do estado, que possuem populações menores, e em pequenas propriedades. Logo, em municípios com populações menores, as despesas com agricultura tendem a ser maiores. Novamente, as transferências intergovernamentais tiveram forte impacto sobre as despesas com agricultura, mesmo sabendo que a maioria dos municípios não destinaram grandes montantes de recursos para o setor no período de análise. Em relação ao impacto dos partidos políticos, os resultados revelaram que a presença de grande parte dos partidos parece não ter impacto nos gastos com agricultura. Quanto ao parâmetro de congestionamento, esse foi igual a 0,1818, o que indica que existiu forte presença de escalas a serem exploradas localmente, no que se trata setor público agricultura. 
Tabela 5 - Determinantes das despesas: agricultura (DESPAGR)

\begin{tabular}{l|c|c|c|c}
\hline \multicolumn{1}{c|}{ Variáveis } & Coeficientes & Erro-padrão & Valor t & P-valor \\
\hline C & $3,1682^{\text {ns }}$ & 24,9190 & 0,1271 & 0,8989 \\
\hline LOG(TXPRICE) & $-0,3147^{* *}$ & 0,0884 & $-3,5592$ & 0,0004 \\
\hline LOG(RENDA) & $-0,0371^{\text {ns }}$ & 0,0317 & $-1,1717$ & 0,2419 \\
\hline LOG(POP) & $-0,1901^{*}$ & 0,0970 & $-1,9597$ & 0,0526 \\
\hline LOG(IFDM) & $-0,2775^{\text {ns }}$ & 0,5829 & $-0,4761$ & 0,6342 \\
\hline LOG(TRANSF) & $1,3493^{* * *}$ & 0,1346 & 10,0213 & 0,0000 \\
\hline LOG(DISTCAPITAL) & $-1,7407^{\text {ns }}$ & 5,5396 & $-0,3142$ & 0,7535 \\
\hline DEM/PFL & $0,6281^{\text {ns }}$ & 0,4059 & 1,5476 & 0,1223 \\
\hline PDT & $-0,2492^{\text {ns }}$ & 0,1653 & $-1,5073$ & 0,1323 \\
\hline PL & $-0,0773^{\text {ns }}$ & 0,2676 & $-0,2888$ & 0,7728 \\
\hline PMDB & $0,1811^{\text {ns }}$ & 0,1986 & 0,9120 & 0,3622 \\
\hline PMN & $0,4203^{\text {ns }}$ & 0,3142 & 1,3378 & 0,1815 \\
\hline PP & $-1,2320^{* *}$ & 0,5429 & $-2,2692$ & 0,0237 \\
\hline PPS & $0,0028^{\text {ns }}$ & 0,2411 & 0,0115 & 0,9908 \\
\hline PR & $-2,1898^{* * *}$ & 0,7171 & $-3,0539$ & 0,0024 \\
\hline PSB & $0,1941^{\mathrm{ns}}$ & 0,1801 & 1,0776 & 0,2817 \\
\hline PSDB & $0,7487^{* * * *}$ & 0,2175 & 3,4425 & 0,0006 \\
\hline PT & $0,4392^{*}$ & 0,2347 & 1,8713 & 0,0619 \\
\hline PTB & $0,1340^{\mathrm{ns}}$ & 0,2089 & 0,6414 & 0,5215 \\
\hline PTDOB & $0,6477^{* * *}$ & 0,1697 & 3,8174 & 0,0002 \\
\hline PAR. CONGESTIONAMENTO & & & 0,1818 & \\
\hline & & &
\end{tabular}

$$
\begin{gathered}
R^{2}=0,9724 \text { Teste } \mathrm{F}(77,527)=6,3080[0,0000] \\
\text { Hausman }=51,6357[0,0001]
\end{gathered}
$$

Fonte: elaborado pelo autor a partir dos dados da pesquisa.

Nota: 1) *** Significativo a $1 \% ; *$ Significativo a $5 \% ; *$ Significativo a $1 \% ;{ }^{\text {ns }}$ Não significativo a $10 \%$;2) L = Indica que as variáveis estão expressas em logaritmos; 3 ) Utilizou-se o método de MQG (cross-section weights), com efeitos fixos.

$\mathrm{Na}$ tabela 6 são apresentados os resultados relativos às despesas com educação e cultura. Os testes $\mathrm{F}$ e de Hausman (ao nível de 10\%) indicaram a utilização do modelo de efeitos fixos. As variáveis RENDA e DISTCAPITAL não foram significativas. Além disso, os partidos políticos PDT, PL, PP, PR e PTB não foram estatisticamente significativos. No que tange a variável TXPRICE, nota-se um efeito positivo e moderado da mesma sobre a demanda por educação e cultura. Isto vem demonstrar certa dificuldade de substituir o bem público pelo privado, neste particular. Destaca-se que, a maior parcela das despesas da variável dependente é 
com educação. No mais, esse fato revela que, dados os altos custos da educação privada no Brasil como um todo e, de certa forma, das atrações culturais, os indivíduos demandam mais serviços de educação e cultura fornecidos pelo estado, mesmo quando ocorre um aumento do esforço fiscal (TXPRICE). A elasticidade-preço da demanda foi inelástica, logo, possíveis políticas locais que elevem o preço do bem público tendem a impactar pouco na demanda pelos mesmos, o que de certa forma daria uma boa margem para possíveis aumentos de impostos pelo governo.

Para a variável POP, o coeficiente foi positivo, demonstrando que, a elevação de $1 \%$ na população dos municípios capixabas aumentou, em média, em 0,1501\% os gastos com educação e cultura. Assim, como esperado, o coeficiente da variável indicou que populações maiores representam maiores despesas públicas. Como mencionado anteriormente, o aumento da população por si só eleva os gastos públicos, especialmente com serviços de educação. A variável IFDM também teve efeito positivo sobre as despesas com educação e cultura. 
Tabela 6 - Determinantes das despesas: educação e cultura (DESPEDUC)

\begin{tabular}{l|c|c|c|c}
\hline \multicolumn{1}{|c|}{ Variáveis } & Coeficientes & Erro-padrão & Valor t & P-valor \\
\hline C & $0,6964^{\text {ns }}$ & 3,9138 & 0,1779 & 0,8588 \\
\hline LOG(TXPRICE) & $0,0474^{* *}$ & 0,0189 & 2,5079 & 0,0126 \\
\hline LOG(RENDA) & $0,0045^{\text {ns }}$ & 0,0048 & 0,9333 & 0,3511 \\
\hline LOG(POP) & $0,1501^{* *}$ & 0,0656 & 2,2872 & 0,0226 \\
\hline LOG(IFDM) & $0,4160^{* * * *}$ & 0,1178 & 3,5303 & 0,0005 \\
\hline LOG(TRANSF) & $0,7867^{* * *}$ & 0,0400 & 19,6656 & 0,0000 \\
\hline LOG(DISTCAPITAL) & $0,2368^{\text {ns }}$ & 0,8664 & 0,2733 & 0,7847 \\
\hline DEM/PFL & $0,0518^{*}$ & 0,0274 & 1,8927 & 0,0589 \\
\hline PDT & $-0,0436^{\text {ns }}$ & 0,0599 & $-0,7283$ & 0,4668 \\
\hline PL & $-0,0281^{\text {ns }}$ & 0,0577 & $-0,4868$ & 0,6266 \\
\hline PMDB & $0,0524^{*}$ & 0,0276 & 1,8949 & 0,0587 \\
\hline PMN & $0,1729^{* * *}$ & 0,0533 & 3,2459 & 0,0012 \\
\hline PP & $-0,0010^{\text {ns }}$ & 0,0270 & $-0,0368$ & 0,9707 \\
\hline PPS & $0,0616^{* *}$ & 0,0278 & 2,2172 & 0,0270 \\
\hline PR & $0,0238^{\text {ns }}$ & 0,0497 & 0,4793 & 0,6319 \\
\hline PSB & $0,0391^{*}$ & 0,0221 & 1,7716 & 0,0770 \\
\hline PSDB & $0,0297^{*}$ & 0,0150 & 1,9769 & 0,0980 \\
\hline PT & $0,0502^{* *}$ & 0,0280 & 1,7915 & 0,0738 \\
\hline PTB & $-0,0086^{\text {ns }}$ & 0,0137 & $-0,6265$ & 0,5313 \\
\hline PTDOB & $0,1691^{* * *}$ & 0,0498 & 3,3979 & 0,0007 \\
\hline PAR. CONGESTIONAMENTO & & 0,0980 & & \\
\hline & & & &
\end{tabular}

$$
R^{2}=0,9724 \text { Teste } \mathrm{F}(77,527)=3,7622[0,0000]
$$

Hausman $=34,0614[0,0181]$

Fonte: elaborado pelo autor a partir dos dados da pesquisa.

Nota: 1$) * * *$ Significativo a $1 \%$; ** Significativo a $5 \%$; * Significativo a $10 \%$; ${ }^{\text {ns }}$ Não significativo a $10 \% ; 2) \mathrm{L}=$ Indica que as variáveis estão expressas em logaritmos; 3 ) Utilizou-se o método de MQG (cross-section weights), com efeitos fixos.

Destaca-se, mais uma vez, a relevância da variável TRANS. Para cada elevação de $1 \%$ nas transferências intergovernamentais ocorreu um crescimento de $0,7867 \%$ nas despesas municipais com educação e cultura. Isso pode refletir que grande parte das transferências intergovernamentais foi destinada pelos municípios às despesas com educação e cultura, principalmente, com educação. Isso, especialmente, naqueles municípios em que a maior parte das receitas orçamentárias é advinda das transferências governamentais. Importante dizer que a educação é vista com uma função prioritária. Logo, existem dispositivos constitucionais e legais, que restringem ou obrigam os governos locais a alocarem uma parcela dos recursos arrecadados localmente ou 
recebidos por transferências de esferas maiores de governo, para essa função.

Em relação aos partidos políticos, mesmo alguns partidos tendo impactos positivos sobre os gastos com educação e cultura, nota-se que os efeitos foram muito pequenos. Isso pode ser devido ao fato de que, independentemente do partido político, os gastos com educação, principalmente, ficaram restritos ao que os mecanismos legais determinam. O parâmetro de congestionamento estimado, 0,0980, demonstra que os serviços de educação e cultura dos municípios do Espírito Santo tiveram ganhos de escala a serem explorados. Isso revela a não rivalidade desses bens, uma vez que, até certo limite, esses serviços tendem a ser compartilhados a reduzidos custos marginais.

$\mathrm{Na}$ tabela 7 podem ser verificados os resultados das estimações para as despesas com seguridade social, que englobam saúde, previdência e assistência social. Os testes F e Hausman (ao nível de 10\%) determinaram a utilização do modelo de efeitos fixos. Como pode ser observado, as variáveis TXPRICE, RENDA, POP, IFDM, TRSNF, DISTCAPITAL foram significantes, assim como os partidos PL, PMDB e PSB. Os coeficientes dos demais partidos foram insignificantes. A variável TXPRICE apresentou sinal positivo e relativamente pequeno. Nesse caso, a análise é similar à apresentada para as dessas com educação e cultura, ou seja, dados os altos custos da saúde privada no Brasil, por exemplo, a substituição do em público pelo privado é muito difícil, o que permite que o governo eleve os impostos sem que haja a queda da demanda por serviços públicos ligados, especialmente, à saúde. Em complemento, o coeficiente da variável renda foi negativo, o que pode indicar que, a partir de certo nível de renda, a população tende a migrar para o setor privado, no que se refere aos itens saúde e previdência, por exemplo. 
Tabela 7 - Determinantes das despesas: seguridade social (DESPSEGUR)

\begin{tabular}{l|c|c|c|c}
\hline \multicolumn{1}{|c|}{ Variáveis } & Coeficientes & Erro-padrão & Valor t & P-valor \\
\hline C & $-5,0606^{\text {ns }}$ & 7,1748 & $-0,7053$ & 0,4809 \\
\hline LOG(TXPRICE) & $0,0646^{* *}$ & 0,0258 & 2,4978 & 0,0128 \\
\hline LOG(RENDA) & $-0,0133^{* *}$ & 0,0062 & $-2,1439$ & 0,0325 \\
\hline LOG(POP) & $0,3297^{* * *}$ & 0,0934 & 3,5318 & 0,0004 \\
\hline LOG(IFDM) & $0,9798^{* * *}$ & 0,1125 & 8,7125 & 0,0000 \\
\hline LOG(TRANSF) & $0,8197^{* * *}$ & 0,0329 & 24,9052 & 0,0000 \\
\hline LOG(DISTCAPITAL) & $1,0849^{\text {ns }}$ & 1,5269 & 0,7105 & 0,4777 \\
\hline DEM/PFL & $0,0180^{\text {ns }}$ & 0,0322 & 0,5592 & 0,5763 \\
\hline PDT & $-0,0353^{\text {ns }}$ & 0,0446 & $-0,7917$ & 0,4289 \\
\hline PL & $-0,2523^{* * *}$ & 0,0774 & $-3,2609$ & 0,0012 \\
\hline PMDB & $0,0816^{* * *}$ & 0,0331 & 2,4609 & 0,0142 \\
\hline PMN & $0,0957^{\text {ns }}$ & 0,0479 & 1,9964 & 0,0464 \\
\hline PP & $-0,0137^{\text {ns }}$ & 0,0475 & $-0,2889$ & 0,7727 \\
\hline PPS & $0,0377^{\text {ns }}$ & 0,0313 & 1,2036 & 0,2293 \\
\hline PR & $0,0616^{\text {ns }}$ & 0,0416 & 1,4821 & 0,1389 \\
\hline PSB & $0,0892^{* * * *}$ & 0,0249 & 3,5874 & 0,0004 \\
\hline PSDB & $-0,0204^{\text {ns }}$ & 0,0308 & $-0,6633$ & 0,5075 \\
\hline PT & $0,0081^{\text {ns }}$ & 0,0371 & 0,2194 & 0,8264 \\
\hline PTB & $0,0347^{\text {ns }}$ & 0,0358 & 0,9699 & 0,3325 \\
\hline PTDOB & $0,0622^{\text {ns }}$ & 0,0383 & 1,6260 & 0,1045 \\
\hline PAR. CONGESTIONAMENTO & & 0,2490 & \\
\hline & & &
\end{tabular}

$$
\begin{gathered}
R^{2}=0,9990 \text { Teste } \mathrm{F}(77,527)=4,5890[0,0000] \\
\text { Hausman }=20,9887[0,0862]
\end{gathered}
$$

\footnotetext{
Fonte: elaborado pelo autor a partir dos dados da pesquisa.

Nota: 1$) * * *$ Significativo a $1 \%$; ** Significativo a $10 \%$; ${ }^{\text {ns }}$ Não significativo a $\left.10 \% ; 2\right) \mathrm{L}=$ Indica que as variáveis estão expressas em logaritmos; 3) Utilizou-se o método de MQG (cross-section weights), com efeitos fixos.
}

As variáveis POP, IFDM e TRANSF apresentaram sinal positivo. Destaca-se, novamente, os efeitos das transferências intergovernamentais sobre as despesas com seguridade social (saúde, previdência e assistência social). Lembrando, mais uma vez, que os gastos com saúde estão vinculados à constituição. No mais, a maior parte dos partidos não impactou nos gastos com seguridade social. Logo, parece que, seja qual for o partido que esteve no poder, as despesas com essa rubrica ficaram limitadas ao que está previsto na legislação. Por fim, o parâmetro de congestionamento foi igual a 0,2490. Esse valor parece não refletir a realidade vivida pelos 
setores públicos de saúde, previdência e assistência social. De acordo com Barcelos (2007), tais setores passam por um grande congestionamento no Brasil, sendo que os mesmos enfrentam deseconomias de escala advindas da sobrecarga a qual parece vivenciar, especialmente, o setor de saúde. Não é objetivo desse estudo, mas, em trabalhos futuros, seria interessante verificar as características desses setores nos municípios do Espírito Santo, a fim de verificar as semelhanças e diferenças em relação ao Brasil.

\section{Conclusões}

O objetivo deste estudo foi estimar a demanda por bens públicos locais (municipais) no estado do Espírito Santo, em nível de despesa total e em nível de despesas funcionais tais como: a) gabinete; b) agricultura; d) educação e cultura; e, e) seguridade social. O trabalho baseou-se no modelo do eleitor mediano, utilizando da técnica econométrica de dados em painel.

Os principais resultados foram os seguintes:

1. No caso das despesas totais, as principais variáveis que explicaram as despesas públicas municipais, TXPRICE, RENDA, POP, IFDM e TRANSF foram significativas. Destaca-se a grande relevância da variável transferências intergovernamentais. Verificou-se que as despesas podem ser impactadas dependendo de qual partido político esteja no poder. O parâmetro de congestionamento revelou que existem economias de escala a serem exploradas para os serviços públicos dos municípios do Espírito Santo;

2. Em relação às despesas de gabinete, as variáveis TXPRICE, RENDA, POP, IFDM, TRSNF e DISTCAPITAL foram significativas. As transferências intergovernamentais revelaram-se relevantes para as despesas de gabinete e o parâmetro de publicização demonstrou que existem ganhos de escala a serem explorados. A variável distância da capital teve efeito, em geral, negativo sobre as despesas públicas. Além disso, independentemente do partido político, as despesas de gabinete tenderam a ser afetadas positivamente;

3. Quanto às despesas com agricultura, constatou-se que as mesmas são afetadas pelas variáveis TXPRICE, POP e TRANSF. As transferências intergovernamentais tiveram forte influência sobre tais gastos. A presença de grande parte dos partidos parece não ter impactado nos gastos com agricultura;

4. No que tange as despesas com educação e cultura, os resultados demonstraram que as variáveis TXPRICE, POP, IFDM e TRANSF foram significativas. Mais uma vez as transferências intergovernamentais foram importantes, e a variável distância da capital apresentou-se significativa. $\mathrm{O}$ coeficiente de congestionamento revelou que existem economias de 
escala a serem exploradas nesses serviços. Os efeitos dos partidos políticos foram muito pequenos;

5. Para as despesas com seguridade social, as variáveis significativas foram: TXPRICE, RENDA, POP, IFDM e TRANSF. As transferências intergovernamentais tiveram expressivo impacto sobre tais despesas. Novamente, seja qual for o partido no poder, as despesas com essa rubrica parecem ter ficado limitadas ao que está previsto na legislação.

De maneira geral, os resultados revelaram que os bens públicos são de primeira necessidade para as comunidades dos municípios capixabas. Despesas mal planejadas tendem a comprometer em o bem-estar das pessoas dessas localidades. Políticas que desenvolvam as comunidades, tendem a melhorar a situação geral da população. Destaca-se o alto grau de dependência dos municípios do Espírito Santo em relação às transferências intergovernamentais, sendo que alguns municípios apresentaram mais de $95 \%$ de sua receita orçamentária proveniente dessas transferências. Isso é corroborado pelo fato de que para todas as despesas, total e por funções, as transferências intergovernamentais afetaram significantemente os gastos dos municípios. Isso deve ser visto com cautela, uma vez que qualquer interrupção no fluxo de transferências pode comprometer as ações dos municípios, haja vista que os mesmos não contam com relevantes receitas próprias.

No mais, notou-se que os coeficientes de congestionamento apresentaram valor inferior à unidade, o que demonstra a presença de economias de escala a serem exploradas para os bens públicos nos municípios capixabas. Isso indica que o consumo dos bens públicos locais no Espírito Santo não está congestionado, e que novos consumidores podem demandá-los, repartindo os custos do fornecimento, sem perda de utilidade. Dessa forma, verifica-se que ainda há espaço para provisão de bens públicos por parte das autoridades dos municípios, especialmente no que se refere aos bens que são obrigações do setor público. Uma ressalva deve ser feita aos serviços de educação e saúde, por exemplo, que na prática parecem sofrer os impactos negativos da falta de uma gestão eficiente do setor público, o que compromete o fornecimento desses serviços de maneira adequada a população e, em certos casos, congestiona a utilização dos mesmos.

Por fim, observa-se que ao longo dos anos as despesas públicas têm aumentado significantemente, porém, na maioria das vezes, somente em termos quantitativos e, não, qualitativos. Sendo assim, este estudo, ao quantificar os determinantes das despesas públicas municipais do Espírito Santo, visa subsidiar as ações dos governos locais, de maneira que seus gastos sejam realizados da maneira mais eficiente possível, ou seja, buscando qualidade e não somente quantidade. 


\section{Referências}

ARONSSON, T.; LUNDBERG, J.; WIKSTRÖM, M. The impact of regional public expenditures on the local decision to spend. Regional Science and Urban Economics, v. 30, n. 2, p. 185-202, 2000. rossef http://dx.doi.org/10.1016/S0166-0462(99)00040-X

BARCELOS, C. L. K. Determinantes da despesa pública local: um estudo empírico dos municípios brasileiros a luz do teorema do eleitor mediano. 2007. $111 \mathrm{f}$. Dissertação (Mestrado em Ciências Contábeis). Programa Multiinstitucional e Inter-regional de Pós-graduação em Ciências Contábeis, Universidade de Brasília, Universidade Federal da Paraíba, Universidade Federal de Pernambuco, Universidade Federal do Rio Grande do Norte, Brasília, 2007.

BERGSTROM, T. C.; GOODMAN, R. P. Private demands for public goods. American Economic Review, v. 63, n 3, p. 280-296, 1973.

BLACK, D. On the rationale of group decision-making. The Journal of Political Economy, v. 56, n. 1, p. 23-34, 1948. Crossef http://dx.doi.org/10.1086/256633

BORCHERDING, T. E.; DEACON, R. T. The demand for the services of non-federal governments. The American Economic Review, v. 62, n 5, p. 891-901, 1972.

BOWEN, $\mathrm{H}$. The interpretation of voting in the allocation of economic resources, Quarterly Journal of Economics, v. 58, n. 1, p. 27-48, 1943. Crossef http://dx.doi. org/10.2307/1885754

COSSIO, F. A. B.; CARVALHO, L. M. Os efeitos expansivos das transferências intergovernamentais e transbordamentos espaciais de despesas públicas: evidências para os municípios brasileiros - 1996, Pesquisa e Planejamento Econômico, Rio de Janeiro, v. 31, n. 1, p. 75-124, 2001.

DOWNS, A. An economic theory of democracy. New York: Harper, 1957. 310 p.

EDWARDS, J. H. Y. Indivisibility and preference for collective provision. Regional Science and Urban Economics. v. 22, n. 4, p. 559-577, 1992. Crossef http://dx.doi. org/10.1016/0166-0462(92)90002-I

GIAMBIAGI, F.; ALÉM, A. C. Finanças públicas: teoria e prática no Brasil. 2 ed. Rio de Janeiro: Elsiever, 2000, 475 p.

GREENE, W. H. Econometrics analysis. 6 ed. New Jersey: Pearson, 2002. 1026 p. 
GRIFFITHS, W. E.; HILL, R. C.; JUDGE, G. G. Learning and practicing econometrics. New York: John Wiley \& Sons Inc. 1993. 866 p.

HAUSMAN, J. A. Specification tests in econometrics. Econometrica, v. 46, n 6, p. 1251-1271. 1978. Crossef http://dx.doi.org/10.2307/1913827

HILL, C.; JUDGE, G; GRIFFITHS, W. Econometria. 3 ed. São Paulo: Saraiva, 2010. $471 \mathrm{p}$.

KENNEDY, P. Manual de econometria. 6 ed. Rio de Janeiro: Elsiever, 2009. 598 p.

MCMILLAN, M. L.; WILSON, W. R.; ARTHUR, L. M. The publicness of local public goods: evidence from Ontario municipalities. The Canadian Journal of Economics, v. 14, n 4, p. 596-608, 1981. Crossef http://dx.doi.org/10.2307/134818

MENDES, C. C. A demanda por serviços públicos municipais no Brasil: a abordagem do eleitor mediano revisada. 2005. 196 f. Tese (Doutorado em Economia). Departamento de Economia, Universidade de Brasília, Brasília. 2005.

MENDES, C. C.; SOUZA, M. C. S. Estimando a demanda por serviços públicos nos municípios brasileiros. Revista Brasileira de Economia, v. 60, n. 3, p. 281-296, 2006. rossef http://dx.doi.org/10.1590/S0034-71402006000300005

PEREIRA, P. T. A teoria da escolha pública (public choice): uma abordagem neoliberal? Análise Social, v. 32, n. 141, p. 419-442, 1997.

POMMEREHNE, W. W. Institutional approaches to public expenditure: empirical evidence from Swiss municipalities. Journal of Public Economics, v. 9, n. 2, p. 255280, 1978. Crossef http://dx.doi.org/10.1016/0047-2727(78)90046-4

REITER, M.; WEICHENRIEDER, A. Are public goods public? A critical survey of the demand estimates for local public services. Finanzarchiv, v. 54, n 3, p. 374408, 1997.

REZENDE, F. A. Finanças públicas. 2 ed. São Paulo: Atlas, 2001. 382 p.

SAMUELSON, P. A. The pure theory of public expenditure. The Review of Economics and Statistics, v. 36, n. 4, p. 387-389, 1954. crossef http://dx.doi.org/10.2307/1925895

SANZ, I.; VELÁZQUEZ, F. J. Determinants of the composition of government expenditure by functions. Madrid: European Economy Group. Working paper 13, 2002. 
SECRETARIA DE ESTADO DA FAZENDA (SEFAZ/ES). Gestão fiscal do Espirito Santo: aprendizado para o futuro. Acesso em: 20 dez. 2016. Disponível em: $<$ http://internet.sefaz.es.gov.br/informacoes/arquivos/publicacoes/projetoaequusbaixa.pdf $>$.

STIGLITZ, J. E. Economics of the public sector. 3 ed. New York: W. W. Norton \& Company, 2000. 823 p.

STOCK, J. H.; WATSON, M. W. Econometria. São Paulo: Pearson (Addison Wesley), 2004. 485 p.

TIEBOUT, C. M. A pure theory of local expenditures. The Journal of Political Economy, v. 64, n. 5, pp. 416-424, 1956. Erossef http://dx.doi.org/10.1086/257839

TURNBULL,G.K.;DJOUNDOURIAN,S.S.Themedianvoterhypothesis:evidence from general purpose local governments. Public Choice, v. 81, n. 3/4, p. 223-240, 1994. Crossef http://dx.doi.org/10.1007/BF01053231

WOOLDRIDGE, J. M. Econometric analysis of cross section and panel data. Cambridge, Mass.: MIT Press, 2002. 735 p.

WOOLDRIDGE, J. M. Introdução à econometria: uma abordagem moderna. 3 ed. São Paulo: Pioneira Thomson Learning, 2006. 684 p. 